\title{
Osteoid Endometrial Metaplasia in Postabortion: About Three Cases at the National Hospital Center of Pikine; Dakar, Senegal
}

Moussa Diallo*, Khalifa Ababacar Gueye, Abdoul Aziz Diouf, Astou Coly Niassy Diallo, Fatoumata Bineta Diallo, Daba Diop, Ndeye Astou Faye, Khalifa Fall, Youssoupha Touré, Codou Sene Seck, Anna Dia Diop, Jacques Raiga and Alassane Diouf

Service de Gynécologie-Obstétrique, Centre Hospitalier National de Pikine, Sénégal

Submission: June 11, 2019 ; Published: June 19, 2019

*Corresponding author: Moussa Diallo, Service de Gynécologie - Obstétrique, Centre Hospitalier National de Pikine, Sénégal

\begin{abstract}
Osteoid metaplasia of the endometrium is a condition characterized by the presence of ectopic bone tissue within the endometrium [1]. It is a rare condition that most often occurs following an interrupted pregnancy. However, its physiopathology still knows some grey areas. Its discovery is most often fortuitous during a secondary infertility check-up in a past interrupted pregnancy; the most frequent circumstance but it can be at the origin of metrorrhagia, dyspareunia, leucorrhoea. These different symptoms are part of chronic aseptic endometritis. We are reporting here, three recently diagnosed cases in our department and using a literature review, we will detail the pathophysiology, symptomatology and management of this pathology.
\end{abstract}

Keywords: Metrorrhagia; Dyspareunia; Leucorrhoea; Endometrial osteoid; Surgical hysteroscopy; Pathology; Pregnancy; Infertility; Fundic hyperechogenic

\section{Introduction}

Endometrial osteoid metaplasia refers to the presence in the endometrium of ectopic bone tissue of mainly fetal origin [1,2]. It was first described by Mayer in 1901 and its incidence is estimated at 0.3 per 1000 infertile women [3]. However, the underestimation of its incidence remains highly probable because it is a little known, under-diagnosed and insufficiently researched pathology. Its diagnosis is based on diagnostic hysteroscopy (with histological examination of the surgical specimen) and its treatment on complete resection during surgical hysteroscopy. Thus, we are reporting here three cases recently handled in our department.

\section{Observation 1}

Mrs. S. B. primigravida nullipara, 41 years old, had consulted for cycle disorders such as menstrual irregularity and minimal metrorrhagia that had progressed over the past few months. Her history includes a voluntary termination of pregnancy at the age of 17 years, the gestational age of which was unknown, and primary infertility of the 13-year-old. The clinical examination found a soft abdomen with no palpable mass. The gynaecological examination finds an endo-uterine bleeding made of red blood with clots of low abundance and a macroscopically healthy cer vix. The vaginal touch returned to a normal-sized uterus. The biological check-up had returned normal and the cervical smear was normal. Pelvic ultrasound had revealed an intrauterine, oval, fundic hyperechogenic image of $15 \mathrm{~mm}$ of major axis, poorly limited with posterior attenuation (posterior shadow cone) (Figure $1)$.

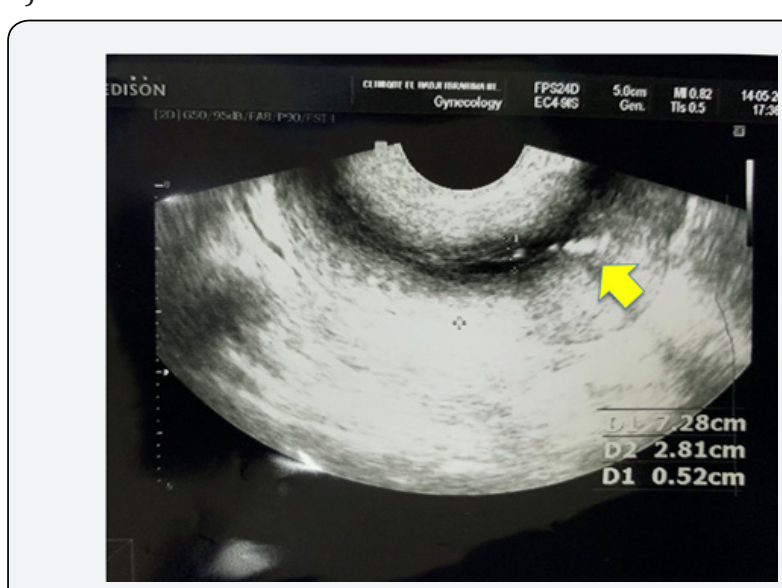

Figure 1: Ultrasound appearance of osteoid metaplasia as hyperechoic images in the uterine cavity with significant posterior attenuation. 


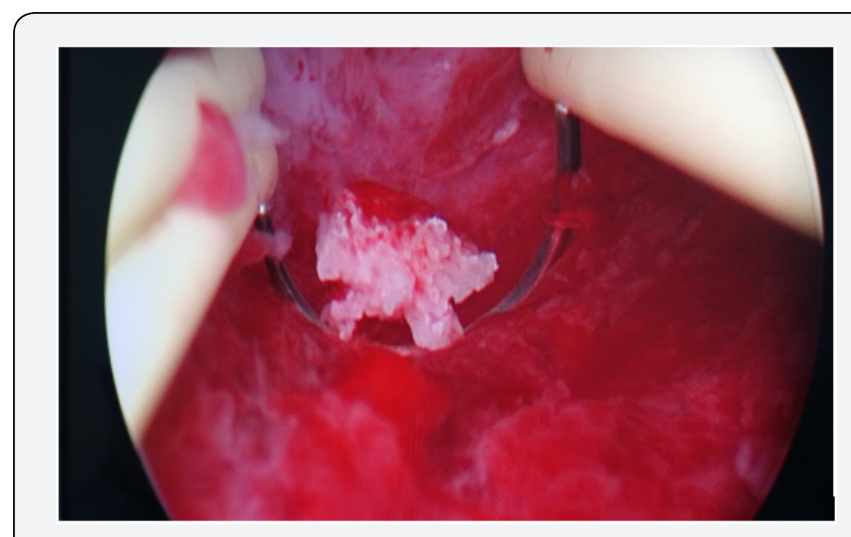

Figure 2: Hysteroscopic appearance of tissue fragments. The tissue is friable and little adherent to the mucosa.

An operative hysteroscopy with general anaesthesia has been proposed. The latter, carried out, had revealed a friable, whitish tissue fragment reminiscent of bone tissue (Figure 2). This fragment, with irregular edges, was firmly attached to a macroscopically healthy uterine mucosa. Its total removal had been done without incident with satisfactory hemostasis. Histological examination of the slices sent in this way had bone tissue fragments made of necrotic spans with disinhabited osteolytic deficiencies with intertrabecular spaces occupied by eosinophilic serosity. The pathologist therefore concluded that there was endometrial ossification and therefore osteoid metaplasia.

\section{Observation 2}

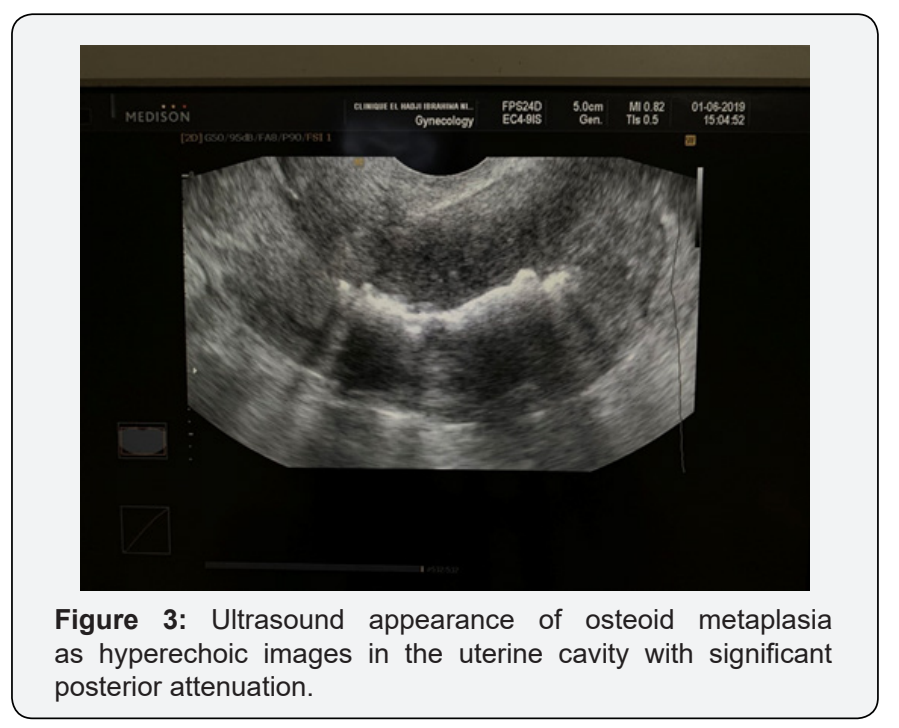

She was a 23-year-old primigravida nullipara patient with menstrual disorders. In her history, there was a miscarriage five years ago, for which she would have had intrauterine aspiration and then medical treatment for incomplete uterine evacuation. The patient's clinical examination was strictly normal at admission except for minimal uterine bleeding. The gynaecological ultrasound then performed, objectified a hyperechogeniic endometrium with a strong posterior attenuation over the entire body portion (Figure 3). Its thickness was $12 \mathrm{~mm}$. In front of this table, an osteoid metaplasia of the endometrium was suspected. A hysteroscopy performed objectified a cervical canal that was partially blocked by incomplete synechia. At the level of the uterine body, there were many whitish elements, sometimes in budding form (Figure 4), sometimes in tubular form (Figure 5), many of which creaked under the biopsy forceps. A complete uterine evacuation was performed. Histological examination of the specimen confirmed the diagnosis of endometrial osteoid metaplasia.

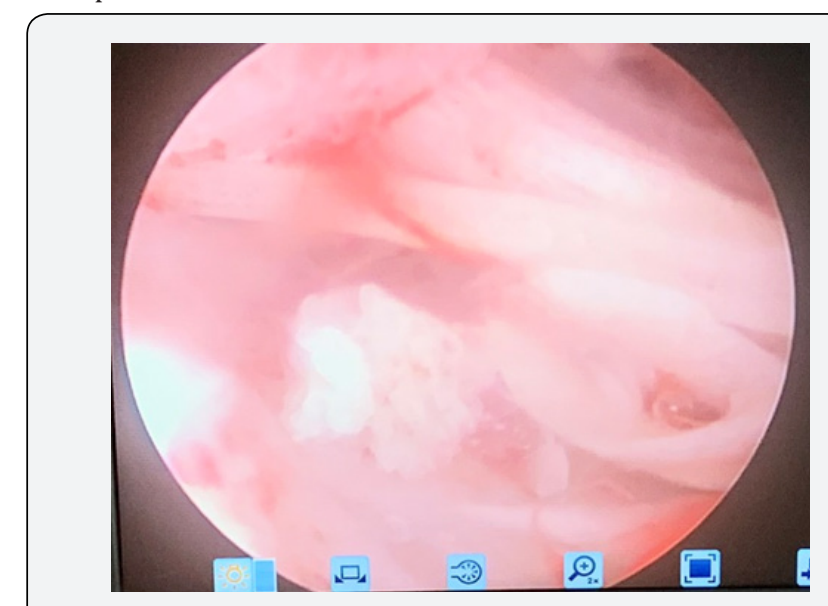

Figure 4: Mise en évidence de formations tubulaires et de formations bourgeonnantes blanchâtres dans la cavité utérine.

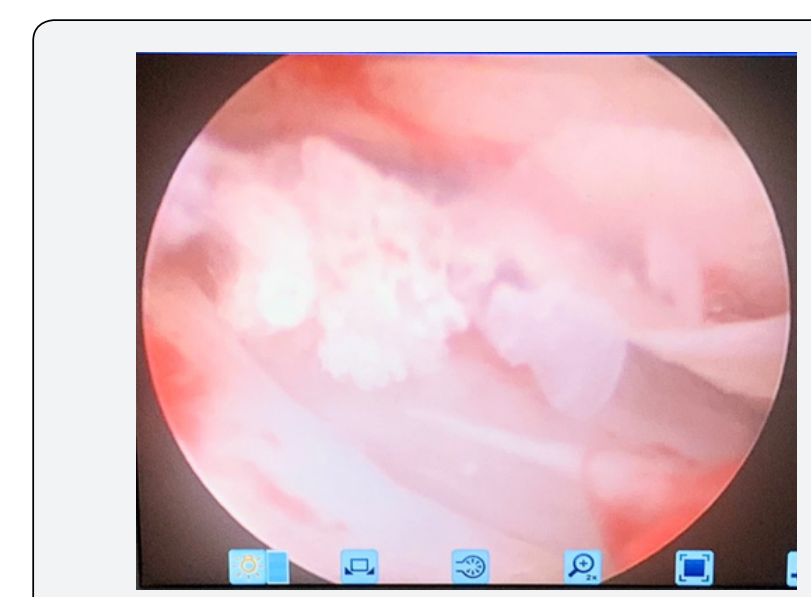

Figure 5: Identification of whitish budding formations in the uterine cavity.

\section{Observation 3}

It was a 29-year-old patient, primiparous with two abortions, who was followed for secondary infertility of the 12-month couple and metrorrhagia. In its history, there was an early abortion that was managed by vaginal administration of misoprostol. No control ultrasound had been performed, as the bleeding had spontaneously faded and uterine evacuation was considered complete. Five months after this episode, she presents metrorrhagia that rebelled against medical treatment. An ultrasound examination had then revealed a hyperechogenic (Figure 3) endometrium at the bottom of the uterus; the myometrium being normal. A hysteroscopy performed had shown a highly suspicious appearance of endometrial osteoid metaplasia (Figure 6). 
The management consisted of evacuation with the hysteroscopy clamp (Figure 7). Once again, the histological examination confirmed the diagnosis of endometrial osteoid metaplasia.
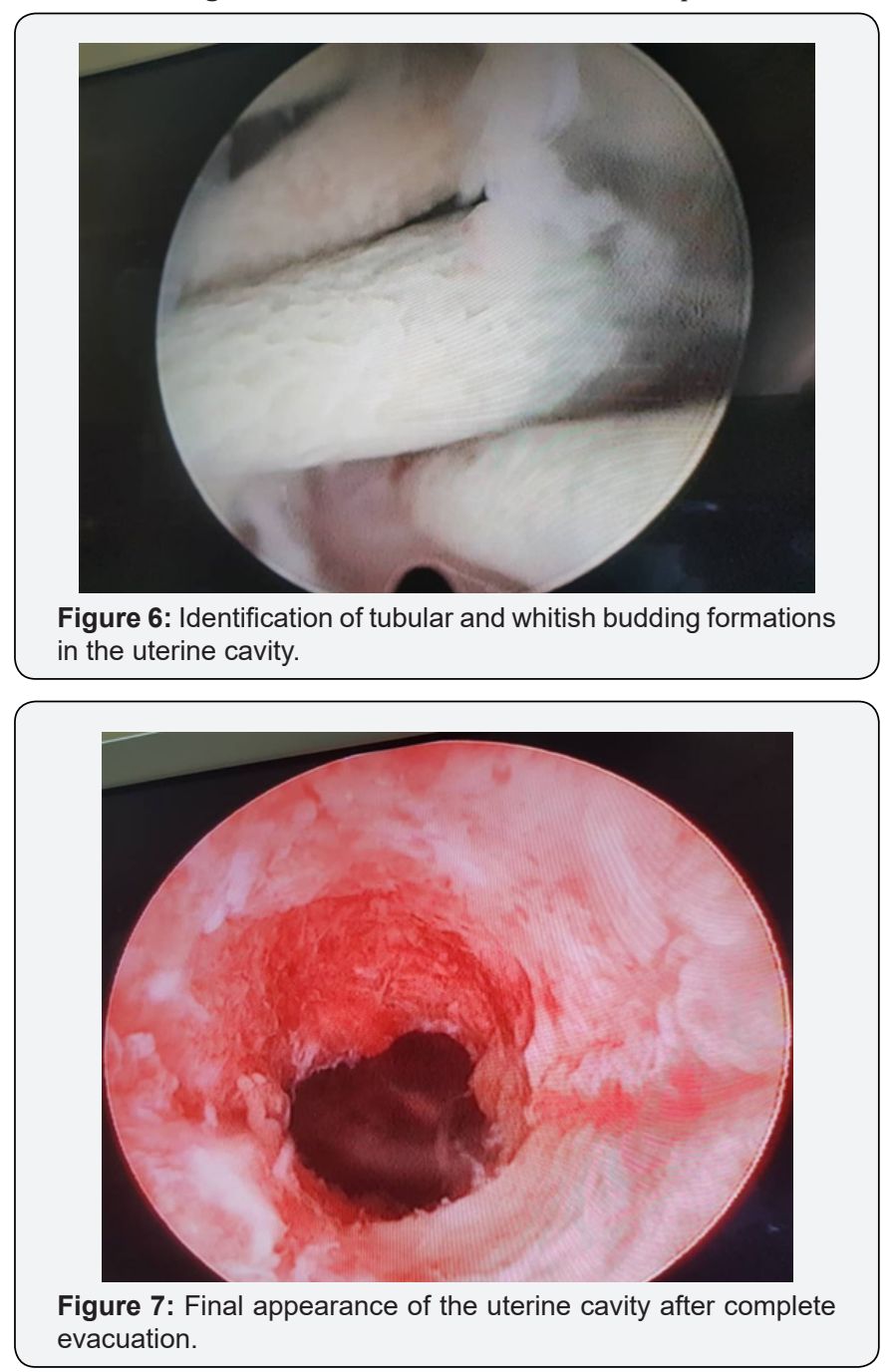

Discussion

Our observation once again shows the diagnostic difficulties of osteoid metaplasia both clinically and paraclinically. Diagnostic and surgical hysteroscopy remain the reference for its diagnosis and management. In our observation, infertility, menstrual cycle disorders and metrorrhagia remained the main reasons for consultation. On the other hand, secondary infertility and chronic pelvic algae in relation to chronic aseptic endometritis remain the main circumstances of discovery, although the literature has reported other possible clinical manifestations such as leucorrhoea, dyspareunia and algomenorrhoea $[4,5]$.

The questioning almost always includes the notion of termination of pregnancy followed by endouterine manoeuvres that can precede the diagnosis by a few months to several years. We first used pelvic ultrasound to support our diagnosis, which showed a hyperechogenic, intrauterine, irregular image with a posterior shadow cone of difficult interpretation. This intracavitary hyperechogenic picture is constantly described as a con- trasting feature with their shape and size, which may suggest other diagnoses ranging from architectural changes (myomas or calcified polyp) to intrauterine foreign bodies (intrauterine device). Hysterography is often normal due to the close radiographic opacity between the lesion and the contrast medium; its diagnostic contribution is discussed [6].

Diagnostic hysteroscopy is probably the key examination to evoke the diagnosis with the identification of whitish, friable and easily detachable bone tissue from the endometrium. The literature reports several different aspects of hysteroscopy [7]:

a) irregular, serrated, tangled, whitish-coloured bone chips with a crab or egg shell appearance,

b) opacification plates embedded in the deep endometrium in contact with the myometrium,

c) small bones sometimes recognizable (shoulder blades, femur...)

Hysteroscopy allows, in addition to diagnosis, the removal of bone fragments, which must be carried out with caution in order not to perforate the uterus. This risk should be assessed on ultrasound by measuring the myometrial thickness separating bone tissue from the uterine serosa. Some authors even recommend performing surgical hysteroscopy under ultrasound control in order to simultaneously visualize the uterine and pelvic cavities, thus ensuring a controlled intervention [8].

In our observation, the notion of termination of pregnancy several years before the appearance of clinical manifestations leads us to believe that the fetus origin is due to incomplete uterine evacuation, but the pathophysiology remains that of the hypotheses. Finally, it should be noted that genital or extragenital ectopic ossification is not uncommon. It is an entity that can sit in all organs (heart, lungs, joints, vessels...). This ossification always occurs within an inflammatory tissue (chronic inflammation most often). It is therefore likely that, similarly, the retention of trophoblast, deciduous or even decidualized mucosa, can create local conditions within an inflammatory endometrium that are conducive to osteoblastic development [9].

\section{Conclusion}

Endometrial osteoid metaplasia is a rare and often unknown condition. Its diagnosis must be evoked in front of any evocative context: secondary infertility with the notion of pregnancy interrupted regardless of the associated clinical manifestations. Its pathophysiology still knows some grey areas and allows the possibility of recurrence to be considered, hence the need for complete resection of the bone parts and post-operative follow-up. Hysteroscopy remains the key to diagnosis and management.

\section{References}

1. Benchimol M, Seince N, Tigazin AL, Carbillon M, Uzan M, et al. (2003) métaplasie ostéoide de l'endomètre à propos d'un cas. Gynécologie obstétrique \& fertilité 31(10): 841-843. 
2. Melius FA, Julian TM, Nagel TC (1991) Prolonged retention of intrauterine bones. Obstet Gynecol 78(5 Pt 2) :919-921.

3. Camus M, Roperty JF, Iloki LH, Tranbaloc P (1990) Ossification endométri- ale. Â propos de cinq observations récentes. J Gynecol Obstet Biol Reprod 19: 295-300.

4. Frydman R, Eibschitz I, Fernandez H, Hamou J (1987) Uterine evaluation by micro- hysteroscopy in IVF candidates. Hum Reprod 2(6): 481485

5. Bhatia NN, Hoshiko MG (1982) Uterine osseous metaplasia. Obstet Gynecol 60(2): 256-259.
6. Taylor PJ, Hamou J, Mencaglia L (1988) Hysteroscopic detection of heterotopic intrauterine bone formation. J Reprod Med 33(4): 337-339.

7. Blanc B, Boubli L (1996) Petite chirurgie hystéroscopique; Endoscopie utérine, Pradel, Germany.

8. Coccia ME, Becattini C, Bracco GL (1996) Ultrasound-guided hysteros-copic management of endometrial osseous metaplasia. Ultrasound Obstet Gynecol 8(2): 134-136.

9. Dawood MY, Jarrett JC (1982) Prolonged intrauterine retention of fetal bones after abortion causing infertility. Am J Obstet Gynecol 143(6): 715-717.

\section{Your next submission with Juniper Publishers will reach you the below assets}

- Quality Editorial service

- Swift Peer Review

- Reprints availability

- E-prints Service

- Manuscript Podcast for convenient understanding

- Global attainment for your research

- Manuscript accessibility in different formats ( Pdf, E-pub, Full Text, Audio)

- Unceasing customer service

Track the below URL for one-step submission https://juniperpublishers.com/online-submission.php 